\title{
Para o mestre com carinho ${ }^{1}$
}

\section{To the master with affection}

Marisa Lajolo ${ }^{2}$

\begin{abstract}
Resumo: O artigo analisa as concepções de literatura e suas implicações humanas e sociais, conforme Antonio Candido desenvolve inicialmente no ensaio "A literatura e a formação do homem" (1972), aprofundando-as no conhecido "O direito à literatura" (1988). Também enfoca o livro Na sala de aula: caderno de análise literária (1985), explicitando, na prática docente do autor, modos de democratizar a leitura e a discussão da literatura.
\end{abstract}

Palavras-chave: Antonio Candido; Literatura; Formação humana; Leitura; Democratização

Abstract: The article analyzes the conceptions of literature and their human and social implications, as Antonio Candido initially develops in the essay "A literatura e a formação do homem" (1972), deepening them in the well-known "“O direito à literatura" (1988). It also focuses on the book Na sala de aula: caderno de análise literária (1985), explaining, in the author's teaching practice, ways of democratizing reading and discussing literature.

Keywords: Antonio Candido; Literature; Human formation; Reading; Democratization

Na obra do Professor Antonio Candido, há três textos aos quais retorno com frequência. Enumero-os aqui na sequência de sua produção/publicação: "A literatura e a formação do homem" ${ }^{3}$, ensaio que se originou de palestra na $24^{\text {a }}$. Reunião Anual (1972) da Sociedade Brasileira pelo Progresso da Ciência (SBPC); Na sala de aula: caderno de análise literária, sua primeira edição é de 1985 e seu título já sugere espaço e situação para a qual os textos nele reunidos foram concebidos; o terceiro é o artigo que inspira o

\footnotetext{
${ }^{1}$ Texto apresentado na OCUPAÇÃO ANTONIO CÂNDIDO no Instituto Cultural Itaú . SP. 25.05.2018. O material da exposição está disponível em http://www.itaucultural.org.br/ocupacao/antonio-candido/

2 Ensaísta, pesquisadora, crítica literária, escritora de literatura juvenil e professora universitária. Atualmente é Professora da Universidade Presbiteriana Mackenzie ( graduação e pós graduação, Letras ) e mantém vínculo como Professor colaborador voluntário na UNICAMP.

${ }^{3}$ Foi publicado em primeira mão na revista Remate de males do Departamento de Teoria Literária da UNICAMP. Disponível em https://doi.org/10.20396/remate.v0i0.8635992
} 


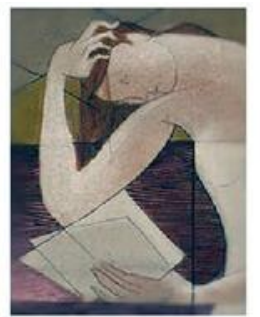

evento que dá nome à Ocupação Antonio Candido, o ensaio "O direito à literatura", palestra na Comissão de Justiça e Paz (1988), incluído no ano seguinte em Direitos Humanos e ... , livro organizado por Antonio Carlos Fester (1989). Posteriormente, o texto frequentou outras publicações e hoje se encontra na coletânea _Vários escritos (2004).

2

Estes três textos têm sua origem ou seu entorno em situações de oralidade. $A$ literatura e a formação do homem e $O$ direito à literatura resultam de palestras. Na sala de aula resulta do preparo de suas aulas, como informa o prefácio:

\begin{abstract}
As versões iniciais destas e muitas outras análises foram redigidas há bastante tempo. Na maioria, entre 1958 e 1960, quando eu lecionava Literatura Brasileira na Faculdade de Filosofia de Assis, SP. À medida que as utilizava nas aulas (...) elas iam sendo acrescidas e modificadas (CANDIDO, 1985, p. 6)
\end{abstract}

\title{
3
}

Penso - com a aval do professor ${ }^{4}$ - que a lapidar formulação de 1988, O direito à literatura $(2004)^{5}$ retoma, desenvolve e radicaliza a reflexão proposta na palestra da década anterior (A literatura e a formação do homem, 1972). Já a partir de seu título, a palestra de 1972 apresenta a literatura como fundamental para a formação do ser humano, apontando "sua função humanizadora, isto é, (...) a capacidade que ela tem de confirmar a humanidade do homem" (2012, p. 81).

Ao longo de seu desenvolvimento, o texto articula o caráter formador da literatura com a ideia de que seres humanos têm "necessidade universal de ficção e de fantasia" (id., p. 82) e que a literatura "é uma das modalidades que funcionam como resposta a esta necessidade universal" (id., p. 83).

Esta função formadora da literatura, formulada a partir de sua pertença ao reino da ficção, da fantasia e da imaginação, desdobra-se. Logo a seguir, o professor sublinha

\footnotetext{
4 Cf. “O direito à literatura”. Op cit. p. 176.

${ }^{5}$ Inspirado neste texto, Aldo Lima organiza a obra $O$ Direito à Literatura (2012), que reproduz o texto do professor.
} 


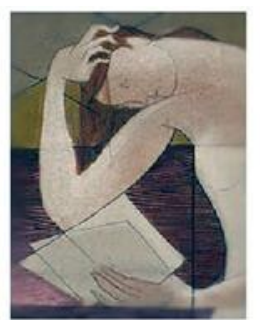

o estabelecimento de laços - nos textos literários - "entre imaginação literária e realidade concreta do mundo"

\section{4}

É a partir desta síntese entre (de um lado) fantasia \& imaginação e ( de outro) a realidade concreta do mundo, que penso ser possível discutir o aprofundamento que o texto de 1988 imprime ao de 1972 :

( ...) se ninguém pode passar vinte e quatro horas sem mergulhar no universo da ficção e da poesia, literatura concebida no sentido amplo a que me referi parece corresponder a uma necessidade universal, que precisa ser satisfeita e cuja satisfação constitui um direito (2004, p. 175 ).

Vale a pena observar que, para o professor, a expressão sentido amplo que envelope o conceito de literatura na citação acima expande e - expandindo - democratiza de forma exponencial o tipo de texto recoberto pela expressão literatura :

Durante a vigília a criação ficcional ou poética, que é a mola da literatura em todos os seus níveis e modalidades, está presente em cada um de nós, analfabeto ou erudito, como anedota, causo, história em quadrinhos, noticiário policial, canção popular, moda de viola, samba carnavalesco. Ela se manifesta desde o devaneio amoroso ou econômico no ônibus, até a atenção fixada na novela de televisão ou na leitura seguida de um romance (2004, p. 174-175).

É com base nesta reflexão (que confere identidade literária também a produtos da indústria cultural ) que o texto se encerra reafirmando que

Uma sociedade justa pressupõe o respeito dos direitos humanos, e a fruição da arte e da literatura em todas as modalidades e em todos os níveis é um direito inalienável ( id., p.191)

\section{5}

Os dois textos de que venho tratando até aqui, em paralelo com sua cerrada argumentação, mencionam alguns escritores: Dostoievsky, Tomás Antonio Gonzaga, Victor Hugo entre outros. 


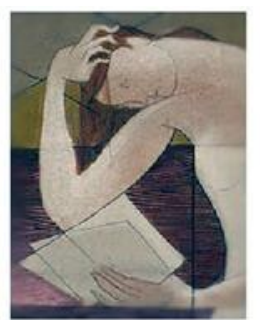

Apesar destas esparsas menções a autores consagrados, A literatura e a formação do homem e $O$ direito à literatura detêm-se, no que talvez se possa chamar de aportes teóricos para uma concepção de literatura como uma das práticas culturais de profundas implicações sociais. Aportes teóricos porque ambos os textos apresentam uma tese: a leitura literária é formadora, reformadora (e será que talvez às vezes também deformadora?) de valores, comportamentos, crenças, sentimentos e normas e, como tal, um direito humano.

\section{6}

Este viés teórico, no entanto, abandona o protagonismo no livro de 1985, Na sala de aula. Nele, o professor arregaça as mangas e encena (e, encenando, ensina) maneiras de, no exercício profissional da docência (e também em textos críticos), democratizar o acesso à literatura.

No prefácio, o livro é apresentado como “instrumento de trabalho” (1985, p. 6). É constituído pela análise de seis poemas ${ }^{6}$, apresentados na sequência de estilos que, por representarem as épocas em que a história literária brasileira geralmente distribui seu objeto, comparecem a cursos da disciplina "literatura brasileira" e a livros didáticos.

7

Desrespeitando a cronologia do livro, vou abri-lo no seu quarto capítulo, que trata do poema Fantástica de Alberto de Oliveira . Adoro este poema! E me desculpo pelo subjetivismo da escolha por uma passagem de Crítica e memória (2004), ensaio em que o professor resgata o direito do crítico ao gosto pessoal e à preferência por um ou por outro texto ${ }^{7}$.

\footnotetext{
${ }^{6}$ Caramuru (Santa Rita Durão); "Lira 77" ( Tomás Antonio Gonzaga); "Meu sonho" (Álvares de Azevedo); "Fantástica" ( Alberto de Oliveira ); "O rondó dos cavalinhos" ( Manuel Bandeira ); "O pastor pianista" ( Murilo Mendes).

${ }^{7}$ (...) um capítulo vivo da periferia da crítica seria o que registrasse com o devido senso de oportunidade a história de nossa experiência afetiva com as obras ( ...) (CANDIDO, 2004 b, p. 33).
} 


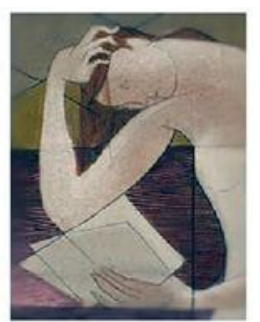

https://seer.ufrgs.br/NauLiteraria

Vol. 16, n. 22019

Dossiê Antonio Candido

A partir da análise que o professor faz do poema de Alberto de Oliveira, vou comentar algumas passagens que ilustram procedimentos discursivos pelos quais - pensotemos uma lição de como democratizar a leitura e a discussão da literatura. Isto é: como torná-las acessíveis. Pois só democratizando a leitura e a discussão da literatura me parece ser possível fomentar a demanda pela literatura e a luta pelo pleno acesso a ela como um direito humano: direito a ser reivindicado, e não concedido por benevolência.

\section{8}

Nas análises do professor, o leitor está sempre explicitamente presente. $\mathrm{Na}$ discussão do poema "Fantástica", que recebe o sugestivo nome de "No coração do silêncio", creio que os leitores ficam com a sensação de que era exatamente a cada um deles que o professor se dirigia. E que era exatamente a ela/ele que o professor atribuía (e aplaudia) uma determinada reação ao texto.

Definindo o poema de Alberto de Oliveira como uma descrição pura e contrapondo este traço à presença de uma primeira pessoa nos dois poemas que, no livro, antecederam o de Alberto de Oliveira (de Tomás Antonio Gonzaga e de Álvares de Azevedo ), o professor se faz intérprete solidário de eventuais reações do seu leitor: "Situado de fora, o leitor vê um quadro feito para existir por si mesmo, autônomo e sem vínculos" (1985, p. 55 ).

Tornando, assim, o leitor seu interlocutor, o professor o traz para dentro do seu texto. Os procedimento textuais responsáveis por tais efeitos de sentido repetem-se em outras passagens da análise de "Fantástica", bem como na análise de outros poemas, como na análise da "Lira 77", de Tomás Antonio Gonzaga e de "O pastor pianista", e Murilo Mendes, respectivamente:

Habituado às neblinas da poesia contemporânea, o leitor fica meio perplexo com este discurso despojado e sem mistério, que parece entregar tudo à primeira vista; mas nota que ele é fruto de uma contensão elaborada ... (id., p. 22, grifos meus).

Com efeito, pensa o leitor, numa planície onde bebem sombras, os pianos podem ser soltos (id., p. 85, grifos meus). 


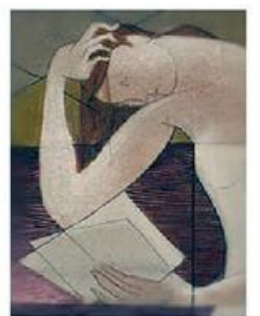

Na sequência da nomeação do leitor como um outsider (situado de fora) do poema de Alberto de Oliveira, reforçando o envolvimento do leitor com o que lê, o professor põe em cena uma primeira pessoa do plural: "Aqui estamos no reinado dos objetos, não dos sujeitos" (id., p.55).

Este nós, generosamente assumido ao longo de quase todos os textos (e também em textos de outros livros ) propicia identificação entre quem escreve (Antonio Candido) e cada leitor que está lendo seu ensaio.

Na análise de Caramuru e de O Rondó dos Cavalinhos a mesma primeira pessoa do plural compartilha interpretações:

De todos os poetas mineiros do século XVIII Durão é o que provavelmente conhecemos melhor como homem (id., p. 8).

Observando a pontuação, percebemos o seguinte (id., p. 70).

Este compartilhamento com seus leitores de pontos de vista apresentados (e, no limite, da autoria da análise?) talvez intensifique o envolvimento e, consequentemente, a adesão de seus leitores-alunos à leitura proposta pela análise, já que ela não é oferecida por uma terceira pessoa - eventualmente distante e superior- mas foi construída pela colaboração do autor com seu leitor.

Ou seja, o leitor sente-se capacitado para ler e discutir textos literários. Como se diria hoje: opera-se aqui o empoderamento do leitor .

\section{0}

A este generoso compartilhamento de pontos de vista soma-se um sucessivo desbastamento de interpretações/afirmações categóricas. Ao invés de leituras e interpretações definitivas, apresentadas como indiscutíveis e verdadeiras, leituras e interpretações propostas pelo professor pautam-se por tom predominantemente sugestivo, hipotético.

Num tempo como o que vivemos hoje por estas bandas, tão sufocado por certezas pétreas, vale a pena observar o respeito com que o professor trata não só seus leitores /alunos mas o próprio tex to que está analisando. 


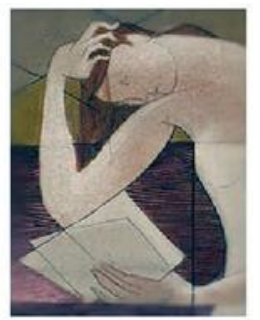

Assumindo, na leitura que apresenta dos textos com que trabalha, que sua leitura não é nem indiscutível, nem definitiva, ao apresentar suas formulações como hipóteses, Antonio Candido aproxima-se de concepções bastante contemporâneas que postulam a abertura da obra literária. Analisando o poema de Alberto de Oliveira, por exemplo, ele limita-se a sinalizar uma possível - apenas possível ! - interpretação para uma bela passagem:

Rio parado é uma contradição em termos, pois a natureza dos rios é fluir. No entanto, existe um nestas condições: o Aqueronte, que, na mitologia grega é ao mesmo tempo barreira defensiva e caminho de ingresso ao reino dos mortos. Isto faz crer que o rio "imoto " cercando o palácio, como fosso protetor, indique a entrada de um lugar desse tipo (id., p. 57).

O mesmo procedimento encontra-se em praticamente todas as outras análises do livro, como por exemplo a dedicada ao poema Meu sonho, de Álvares de Azevedo: O sonho deste poema parece mais um pesadelo ... (id., p. 48).

Mais adiante, a propósito de "O pastor pianista", o advérbio talvez e o futuro do pretérito relativizam qualquer traço impositivo da leitura apresentada: Entre os pianos e os homens talvez haja uma correlação mais funda, que unificaria de maneira dialética a parte impertinente e a pertinente (id., p. 95).

Outros títulos da obra de professor valem-se de procedimento idêntico. Em texto de $1943^{8}$, a propósito de Stendhal, afirmações categóricas são substituídas por um enunciado que manifesta em plenitude o procedimento aqui apontado: "talvez se possa dizer que é um psicólogo mais completo que ambos (Benjamin Constant e Balzac, grifo meu), estando a chave de seus livros ... (1959, p. 60).

Também um dos documentos expostos na Ocupação Antonio Candido materializa, no manuscrito à margem, a correção pretendida para o texto impresso, o que ilustra a extensão deste procedimento na produção intelectual do professor, inclusive em áreas que não se referem à literatura .

\footnotetext{
${ }^{8}$ Trata-se de 'Uma dimensão entre outras", publicado em O observador literário (1959).
} 


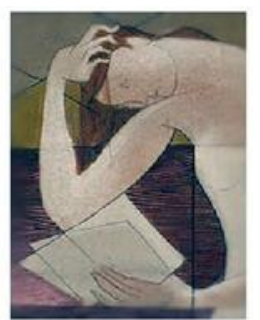

Trata-se de separata do artigo "Possíveis raízes indígenas de uma dança popular" (CANDIDO, 1956), publicado na Revista de Antropologia da Faculdade de Filosofia, Ciências e Letras da USP:

\begin{tabular}{|l|l|}
\hline Versão publicada & Correção manuscrita à margem \\
\hline $\begin{array}{l}\text { Com efeito, dentro da melhor } \\
\text { verossimilhança, esta se deu por } \\
\text { intermédio da catequese jesuítica, tendo se } \\
\text { desenvolvido em ... }\end{array}$ & $\begin{array}{l}\text { Com efeito, o mais plausível é que esta } \\
\text { tenha ocorrido por meio da catequese } \\
\text { jesuítica, tendo se desenvolvido em ... }\end{array}$ \\
\hline \multicolumn{2}{|c|}{ esta se deu > o mais plausível é que esta tenha ocorrido ... } \\
\hline
\end{tabular}

11

Em “A compreensão da realidade", texto de 1957, publicado em $O$ Observador Literário, publicado em 1959, a respeito de José Lins do Rego, o recurso se alarga, deixando de manifestar-se a propósito de uma ou de outra passagem interpretativa, e recobrindo a interpretação/crítica em sua totalidade: "Este artigo pretende sugerir que a sua obra se desenvolveu por altos e baixos..." (1959, p. 31). O segmento pretende sugerir da transcrição acima substitui, com vantagem, a assertividade de provar, demonstrar, afirmar que pontilham tantos textos críticos".

Como se vê, já se faz presente, nas primeiras publicações do professor - então um jovem sociólogo que fazia crítica literária em jornais paulistanos enquanto lecionava em Assis - a consciência da importância do leitor/público em assuntos de literatura. Em artigo de 1957, rebatizado em Literatura e sociedade, de 1965, como "Literatura e vida social" o professor aponta os três elementos fundamentais da comunicação artística: autor/obra/público.

Articula-se com este texto mais antigo a meridiana clareza com que, na Formação da literatura brasileira - cuja primeira edição é de 1959 - o professor, a propósito da literatura brasileira, expõe a noção de sistema literário. No segundo parágrafo do capítulo de abertura, lê-se que a partir do conceito de "literatura como um sistema de obras ligadas por denominadores comuns" pode-se pensar na literatura como 


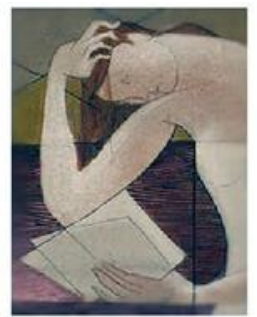

https://seer.ufrgs.br/NauLiteraria

Vol. 16, n. 22019

um conjunto de produtores literários mais ou menos conscientes de seu papel, um conjunto de receptores, formando os diferentes tipos de público, sem os quais a obra não vive ; (...) um mecanismo transmissor ( de modo geral uma linguagem traduzida em estilos) que liga uns a outros (2006, p. 25).

É nesta acurada e precoce percepção da importância do leitor em discussões / reflexões sobre a literatura que - penso - ancora-se a ideia retomada respectivamente em A literatura e a formação do homem (1972) e em O direito à literatura (1988) .

12

Se é verossímil este percurso do professor na discussão da importância da literatura como formadora e, portanto, como um direito humano entrevista recente confere nova e instigante inflexão ao tema.

Trata-se de entrevista ao jornal Brasil de Fato publicada em agosto de 2011, que reforça a importância da limpidez do texto crítico como fator essencial para a discussão e ensino da literatura :

\begin{abstract}
Acho que a clareza é um respeito pelo próximo, um respeito pelo leitor. Sempre achei, eu e alguns colegas, que, quando se trata de ciências humanas, apesar de serem chamadas de ciências, são ligadas à nossa humanidade, de maneira que não deve haver jargão científico. Posso dizer o que tenho para dizer nas humanidades com a linguagem comum. (...) acho que a clareza é necessária inclusive para poder divulgar a mensagem, a mensagem deixar de ser um privilégio e se tornar um bem comum (CANDIDO, 2011) .
\end{abstract}

Uma coisa que sempre me preocupou muito é que os teóricos da literatura dizem: é preciso fazer isso, mas não fazem.

O professor Antonio Candido faz...

Faz não apenas no que diz, mas no como diz o que diz...

E será muito bom que aprendamos com ele.

\footnotetext{
${ }^{9} \mathrm{~A}$ entrevista, na íntegra e com comentários de leitores, está disponível em https://www.brasildefato.com.br/node/6819/
} 


\section{Referências}

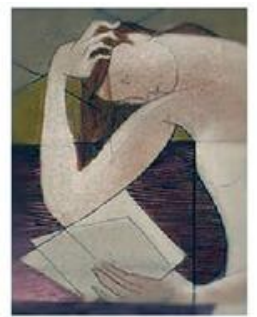

CANDIDO, Antonio. A literatura e a formação do homem. Remate de Males, $3 \mathrm{dez}$. 2012. Disponível em https://periodicos.sbu.unicamp.br/ojs/index.php/remate/article/view/8635992/3701

CANDIDO, Antonio. Crítica e memória. In: O albatroz e o chinês. São Paulo, Rio de Janeiro: Ouro sobre azul, 2004.

CANDIDO, Antonio. Formação da literatura brasileira. São Paulo, Rio de Janeiro: Ouro sobre azul, 2006.

CANDIDO, Antonio. Literatura de sociedade. São Paulo: Duas Cidades, Rio de Janeiro: Ouro sobre azul, 2014.

CANDIDO, Antonio. Na sala de aula: caderno de análise literária: São Paulo: Ática, 1985.

CANDIDO, Antonio. O direito à literatura. In: . FESTER, Antonio Carlos ( org.). Direitos Humanos e ... São Paulo: Editora Brasiliense, 1989.

CANDIDO, Antonio. Vários escritos. São Paulo: Duas Cidades, Rio de Janeiro: Ouro sobre azul, 2004.

CANDIDO, Antonio. Possíveis raízes indígenas de uma dança popular. Revista de Antropologia, v. 4, n. 1, p. 1-24, 11 jun. 1956.

CANDIDO, Antonio. Uma dimensão entre outras. In: O observador literário. São Paulo: Conselho Estadual de Cultura, 1959 .

LIMA, Aldo Lima. O Direito à Literatura. Recife: Editora da UFPE, 2012. 